\title{
UBE2J2 promotes hepatocellular carcinoma cell epithelial- mesenchymal transition and invasion in vitro
}

\author{
Shaopeng Chen ${ }^{1}$, Ying Tan ${ }^{1}$, Haihua Deng ${ }^{4}$, Zhifa Shen ${ }^{3}$, Yanhong Liu ${ }^{1}$, Pan Wu ${ }^{1}$, \\ Chunyan $\operatorname{Tan}^{1}$ and Yuyang Jiang ${ }^{1,2}$ \\ ${ }^{1}$ Graduate School at Shenzhen, Tsinghua University, Shenzhen 518055, China \\ ${ }^{2}$ School of Pharmaceutical Sciences, Tsinghua University, Beijing, 100084, P. R. China \\ ${ }^{3}$ Key Laboratory of Laboratory Medicine, Ministry of Education of China, Zhejiang Provincial Key Laboratory of Medical \\ Genetics, School of Laboratory Medicine and Life Sciences, Wenzhou Medical University, Wenzhou 325035, China \\ ${ }^{4}$ Fuyong Hospital, Shenzhen, 518055, China \\ Correspondence to: Chunyan Tan, email: tancy@sz.tsinghua.edu.cn \\ Yuyang Jiang, email: jiangyy@sz.tsinghua.edu.cn
}

Keywords: hepatocellular carcinoma, UBE2J2, epithelial-mesenchymal transition, EGFR, invasion

Received: December 20, $2016 \quad$ Accepted: April 12, $2017 \quad$ Published: May 03, 2017

Copyright: Chen et al. This is an open-access article distributed under the terms of the Creative Commons Attribution License 3.0 (CC BY 3.0), which permits unrestricted use, distribution, and reproduction in any medium, provided the original author and source are credited.

\section{ABSTRACT}

Ubiquitin-conjugating enzyme E2 J2 (UBE2J2) is an ubiquitin proteasome component that responds to proteotoxic stress. We found that UBE2J2 was highly expressed in cellular protrusions of HCCLM3 metastatic hepatocellular carcinoma (HC) cells. Immunohistochemical analyses showed that UBE2J2 was expressed at higher levels in HC patient tissues than in corresponding non-tumor tissues. Because cellular protrusions are important for cell invasion, we hypothesized that UBE2J2 promotes HC cell invasion. We used chip-based surface plasmon resonance (SPR) to assess possible mechanisms of UBE2J2-regulated HCCLM3 cell invasion. We found that p-EGFR interacted with UBE2J2, and this finding was confirmed by co-immunoprecipitation analysis. UBE2J2 overexpression activated endothelial-mesenchymal transition in the non-invasive SMMC7721 HC cell line, and promoted invasion. UBE2J2 silencing reduced HCCLM3 cell invasion and endocytosis, and downregulated p-EGFR expression. p-EGFR inhibition by lapatinib reduced UBE2J2-promoted cell invasion, suggesting p-EGFR is important for UBE2J2-mediated HCCLM3 cell invasion. These findings demonstrate that endocytosis by HC cells is closely related to invasion, and may provide new anti-HC therapeutic targets. UBE2J2 may also be a novel biomarker for clinical HC diagnosis.

\section{INTRODUCTION}

Hepatocellular carcinoma (HC) is one of the most common cancers worldwide $[1,2]$. Metastasis is the primary cause of cancer patient death [3], and $\mathrm{HC}$ diagnostic and therapeutic outcomes remain unsatisfactory[2]. Additional studies of the molecular mechanisms underlying $\mathrm{HC}$ cell metastasis, and new anti$\mathrm{HC}$ therapeutic targets are urgently needed [2].

Cell invasion is closely related to tumor metastasis [4]. Before invasion, most malignant tumor cells undergo epithelial-mesenchymal transition (EMT) to detach from surrounding tissue $[5,6]$. Biomarkers, including E-cadherin, snail, slug, vimentin, CLDN-1, and N-cadherin, can be used to detect EMT or MET (reverse process of EMT). Cellular protrusions can drive cancer cells to dissociate from their surroundings and penetrate into the vasculature [7]. Highly dynamic actins assembled by the Arp $2 / 3$ complex and formins, along with dynamin and cortactin, both membrane trafficking machinery components, reportedly accumulate in finger-like protrusions [8-10]. Direct RNA sequencing (DRS) analysis of hepatocellular carcinoma cell protrusions will enhance our understanding of liver tumor cell metastasis and invasion.

Most misfolded proteins and extracellular proteins internalized via endocytosis are degraded through the ubiquitin proteasome pathway [11]. Ubiquitin-conjugating 
enzyme E2 J2 (UBE2J2) is an ubiquitin proteasome component that responds to proteotoxic stress [12-13]. As an endoplasmic reticulum-localized ubiquitinconjugating enzyme, UBE2J2 associates with ubiquitin ligases, including TEB4 [14], parkin [15], CHIP [16], and cIAP1 [17], to promote proteasomal degradation [18]. The UBE2J2 hydrophobic carboxyl terminus region reportedly stabilizes UBE2J2 and mediates insertion of proteins into the ER membrane [18]. UBE2J2 also interacts with c-IAP1 to support TNF-R2-mediated TRAF2 ubiquitination and degradation [17]. So far, little evidence has implicated UBE2J2 in cell invasion.

This study found that UBE2J2 was highly expressed in HCCLM3 cell protrusions. We investigated mechanisms of UBE2J2-regulated HCCLM3 cell invasion and the relationship between endocytosis and cell invasion, providing new insights into $\mathrm{HC}$ metastasis and invasion regulation.

\section{RESULTS}

\section{UBE2J2 is highly expressed in HCCLM3 cell protrusions}

We isolated cellular protrusions and cell bodies from HCCLM3 (a highly metastatic $\mathrm{HC}$ cell line) and SMMC7721 cells (a low metastatic HC cell line) via Boyden chamber isolation assay as described previously [19] (Figure 1). More than 7500 genes were sequenced using DRS and listed according their expression ratios in HPs (HCCLM3 protrusions) versus HBs (HCCLM3 cell bodies). Table 1 lists the 50 genes with the highest HP/ HB expression ratios. PYCARD is related to inflammatory and apoptotic signaling pathways [20], and STXBP2, ATP6V0D1, and UBE2J2 are responsible for endocytosis [21-24]. Our DRS results suggest that endocytosis is related to $\mathrm{HC}$ cell metastasis and invasion.

Protein lysates were analyzed using western blotting (Figure 2A-2B). UBE2J2 was more highly expressed in HCCLM3 cell protrusions than in SMMC7721 cells and cell bodies. RT-qPCR results revealed that UBE2J2 transcription rates were greater in HCCLM3 protrusions than in cell bodies and SMMC7721 cells (Figure 2C).

\section{UBE2J2 is enriched in tumor tissues}

Forty-five invasive $\mathrm{HC}$ and corresponding non-tumor tissue samples were analyzed immunohistochemically (Figure 3). Staining results were scored and classified using the five-point scoring system as described [25]. Positive UBE2J2 staining (score $>2$ ) was detected in 42/45 (93.3\%) metastatic HC samples, and 13/45 (28.9\%) corresponding non-tumor tissues, $(P<0.01$, Figure 3$)$. These results show that UBE2J2 is highly expressed in metastatic HC tissues.

\section{UBE2J2 knockdown decreases HCCLM3 cell invasion}

UBE2J2 was silenced using specific siRNAs in HCCLM3 cells, and cell invasion was measured using the Boyden chamber assay. The number of migrated cells was lower in UBE2J2-silenced cells than in controls (Figure 4), indicating that UBE2J2 regulates HCCLM3 cell invasion.

\section{UBE2J2 knockdown induces MET in HCCLM3 cells}

EMT/MET biomarkers were used to detect the effects of UBE2J2 on the EMT/MET processes via western blotting. UBE2J2 knockdown downregulated ZO-1, $\beta$-catenin, CLDN-1, N-cadherin, slug, snail, MMP-9, and vimentin by $80.7 \%, 94.6 \%, 80.7 \%, 59.4 \%, 33.1 \%, 37.1 \%$, $78.1 \%$, and $78.3 \%$, respectively (Figure 5 ). E-cadherin expression was upregulated by $175.4 \%$ (Figure 5). These results suggest that UBE2J2 knockdown induces MET in HCCLM3 cells.

\section{UBE2J2 overexpression activates SMMC7721 cell EMT and promotes invasion}

An UBE2J2 expression plasmid was transfected into SMMC7721 cells. After $24 \mathrm{~h}$, cell lysates were collected and analyzed via western blotting using EMT biomarker antibodies to examine the effects of UBE2J2 on EMT (Figure 6A). UBE2J2 overexpression (by 158\%), $\beta$-catenin, CLDN-1, N-cadherin, slug, snail, vimentin, MMP-9, and ZO-1 levels increased by $226.89 \%, 256.15 \%$, $188.23 \%, 289.25 \%, 159.34 \%, 200.29 \%, 197.3 \%$, and $62.07 \%$, respectively (Figure 6B). E-cadherin expression was reduced to $32.16 \%$ (Figure 6B). These results suggest that UBE2J2 overexpression induced EMT in SMMC7721 cells. UBE2J2 overexpression also resulted in higher numbers of migrated cells ( $735 \pm 32)$ than controls (343 \pm 28$)$ (Figure 6C).

\section{UBE2J2 binds p-EGFR}

Chip-based surface plasmon resonance (SPR) was used to screen for potential UBE2J2-associating proteins. SPR biosensors monitor refractive index (measured in resonance units, RU) alterations caused by binding of analytes to ligands immobilized on sensor chips [26]. Anti-UBE2J2 antibody was immobilized on CM5 sensor chips. RU values increased from 2300 to 3800 when cell-extracted proteins bound the immobilized antibody (Figure 7A). An RU increase from 3800 to 5100 indicated that p-EGFR bound UBE2J2 (Figure 7A-7B). Co-IP analysis results further confirmed that p-EGFR binds UBE2J2 (Figure 7C-7E). 
Table 1: DRS of HCCLM3 and SMMC7721 cellular protrusion and cell bodies

\begin{tabular}{|c|c|c|c|c|}
\hline Gene ID & Symbol & HP/HB & SP/SB & Reported on invasion \\
\hline 1382 & CRABP2 & 2.51 & l & $\sqrt{ }$ \\
\hline 10381 & TUBB3 & 2.25 & / & $\sqrt{ }$ \\
\hline 9022 & CLIC3 & 2.24 & / & $\sqrt{ }$ \\
\hline 7001 & PRDX2 & 2.22 & 1.19 & $\sqrt{ }$ \\
\hline 5499 & PPP1CA & 2.21 & 1.46 & $\sqrt{ }$ \\
\hline 226 & ALDOA & 2.19 & 1.27 & $\sqrt{ }$ \\
\hline 6237 & RRAS & 2.14 & 1.18 & $\sqrt{ }$ \\
\hline 3217 & HOXB7 & 2.11 & 1.06 & $\sqrt{ }$ \\
\hline 6813 & STXBP2 & 2.07 & 1.39 & - \\
\hline 29108 & PYCARD & 2.07 & l & - \\
\hline 9114 & ATP6V0D1 & 2.07 & 1.36 & - \\
\hline 71 & ACTG1 & 2.01 & 1 & $\sqrt{ }$ \\
\hline 256281 & NUDT14 & 2.00 & l & $\sqrt{ }$ \\
\hline 7086 & TKT & 1.96 & 1.43 & $\sqrt{ }$ \\
\hline 3880 & KRT19 & 1.91 & l & $\sqrt{ }$ \\
\hline 5730 & PTGDS & 1.90 & l & $\sqrt{ }$ \\
\hline 1397 & CRIP2 & 1.90 & l & $\sqrt{ }$ \\
\hline 11040 & PIM2 & 1.90 & 0.98 & $\sqrt{ }$ \\
\hline 118424 & UBE2J2 & 1.89 & 1.09 & - \\
\hline 293 & SLC25A6 & 1.89 & 1.29 & - \\
\hline 2010 & EMD & 1.88 & 1.30 & $\sqrt{ }$ \\
\hline 9168 & TMSB10 & 1.88 & 1.42 & $\sqrt{ }$ \\
\hline 10636 & RGS14 & 1.88 & 1 & $\sqrt{ }$ \\
\hline 991 & $\mathrm{CDC} 20$ & 1.87 & 1.23 & $\sqrt{ }$ \\
\hline 26099 & SZRD1 & 1.85 & 1.29 & - \\
\hline 4282 & MIF & 1.85 & 1.30 & $\sqrt{ }$ \\
\hline 51282 & SCAND1 & 1.84 & 0.98 & - \\
\hline 113452 & TMEM54 & 1.84 & l & - \\
\hline 7284 & TUFM & 1.83 & 1.37 & - \\
\hline 79629 & OCEL1 & 1.82 & 1.27 & - \\
\hline 7283 & TUBG1 & 1.82 & 1.13 & $\sqrt{ }$ \\
\hline 3611 & ILK & 1.82 & 1.31 & $\sqrt{ }$ \\
\hline 5003 & SLC22A18AS & 1.82 & l & - \\
\hline 1465 & CSRP1 & 1.81 & 1.33 & $\sqrt{ }$ \\
\hline 10749 & KIF1C & 1.81 & 1.32 & $\sqrt{ }$ \\
\hline 5696 & PSMB8 & 1.81 & 1.45 & - \\
\hline 55365 & TMEM176A & 1.81 & I & - \\
\hline
\end{tabular}




\begin{tabular}{lcccc}
\hline Gene ID & Symbol & HP/HB & SP/SB & Reported on invasion \\
\hline 6187 & RPS2 & 1.80 & $/$ & - \\
217 & ALDH2 & 1.80 & 1.25 & - \\
10238 & DCAF7 & 1.79 & 1.28 & - \\
84885 & ZDHHC12 & 1.79 & 1.33 & - \\
7280 & TUBB2A & 1.79 & $/$ & $\sqrt{ }$ \\
27338 & UBE2S & 1.78 & 1.22 & $\sqrt{ }$ \\
9235 & IL32 & 1.78 & 1.01 & $\sqrt{ }$ \\
3669 & ISG20 & 1.77 & $/$ & - \\
1984 & EIF5A & 1.77 & 1.21 & $\sqrt{ }$ \\
1616 & DAXX & 1.76 & 1.02 & $\sqrt{ }$ \\
6920 & TCEA3 & 1.76 & 1.26 & - \\
6015 & RING1 & 1.75 & 0.97 & $\sqrt{ }$ \\
92170 & MTG1 & 1.75 & $/$ & - \\
\hline
\end{tabular}

Abbreviations: HP: HCCLM3 protrusions; HB: HCCLM3 cell bodies; SP: SMMC7721 protrusions; SB: SMMC7721 cell bodies; “"”: gene could not be detected; “-”: little report of the given gene with respect to cell invasion; " $\sqrt{ }$ ”: reports of the given gene with respect to cell invasion.

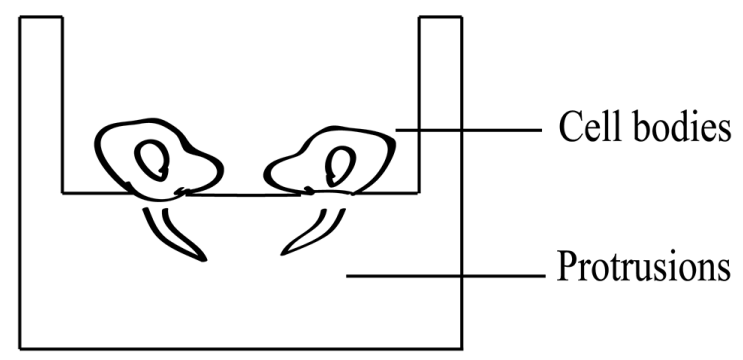

Figure 1: Cellular protrusion and cell body isolation. HCCLM3 and SMMC7721 cells were seeded on invasion inserts with $1 \mu \mathrm{m}$ (diameter) pore membranes, allowing only protrusions to pass through. Twelve $\mathrm{h}$ after cells reached confluence, cellular protrusions and cell bodies were isolated using cell scrapers, and total RNA and proteins were collected.

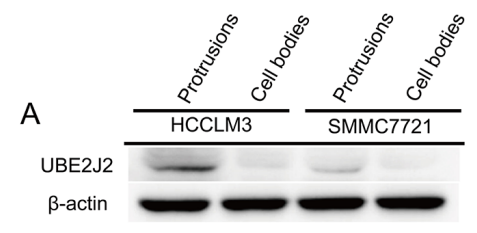

B

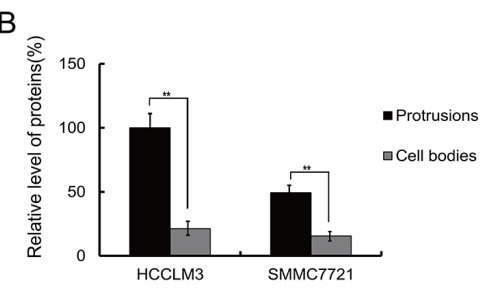

C

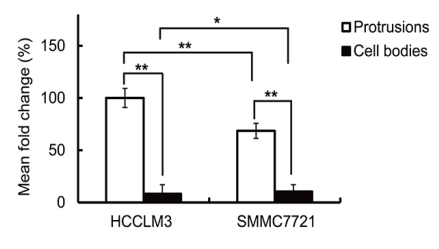

Figure 2: UBE2J2 expression in HCCLM3 and SMMC7721 cell protrusions and cell bodies. (A) Western blot analysis of UBE2J2 in HCCLM3 and SMMC7721 cell protrusions and cell bodies. $\beta$-actin was used as the loading control. (B) Densitometric analysis. Results are shown with respect to control. (C)Cellular protrusion and cell body mRNA was quantified by RT-qPCR. GAPDH was used as an internal control. $* P<0.05,{ }^{* *} P<0.01$ vs. control. 


\section{UBE2J2 and p-EGFR were enriched in HC tissues}

Serial sections of metastasized HC tissues were stained using anti-UBE2J2 and anti-p-EGFR antibodies (Figure 8A). UBE2J2-positive and p-EGFR-positive staining was observed in $86.7 \%(13 / 15)$ and $73.3 \%(11 / 15)$ of samples, respectively (Figure $8 \mathrm{~B}, P<0.01$ ), indicating that $\mathrm{p}$-EGFR and UBE2J2 were highly expressed in $\mathrm{HC}$ tissues. The highest-scoring UBE2J2 and p-EGFR positive staining locations are indicated by white arrows (Figure 8A).

\section{UBE2J2 knockdown downregulates p-EGFR}

UBE2J2-knockdown HCCLM3 cells were immunofluorescently stained $24 \mathrm{~h}$ post-transfection. p-EGFR was downregulated in treated cells compared with controls
(Figure 9A). Transferrin, an endocytosis indicator, was also downregulated in UBE2J2-silenced cells (Figure 9B). Western blotting results showed that UBE2J2 knockdown reduced p-EGFR expression (Figure 9C) to $24 \%$ of control levels (Figure 9D). These results together indicate that UBE2J2 promotes p-EGFR expression and endocytosis.

\section{Lapatinib attenuates UBE2J2-mediated cell invasion}

Lapatinib (10 nM), a p-EGFR inhibitor [27], was used to explore the role of p-EGFR in UBE2J2-regulated cell invasion. Lapatinib-mediated p-EGFR suppression attenuated the effects of UBE2J2 on cell invasion (Figure 10A-10B). Western blotting confirmed that Lapatinib suppressed p-EGFR, resulting in E-cadherin downregulation (Figure 9C). p-EGFR inhibition also reduced the suppression on E-cadherin by UBE2J2

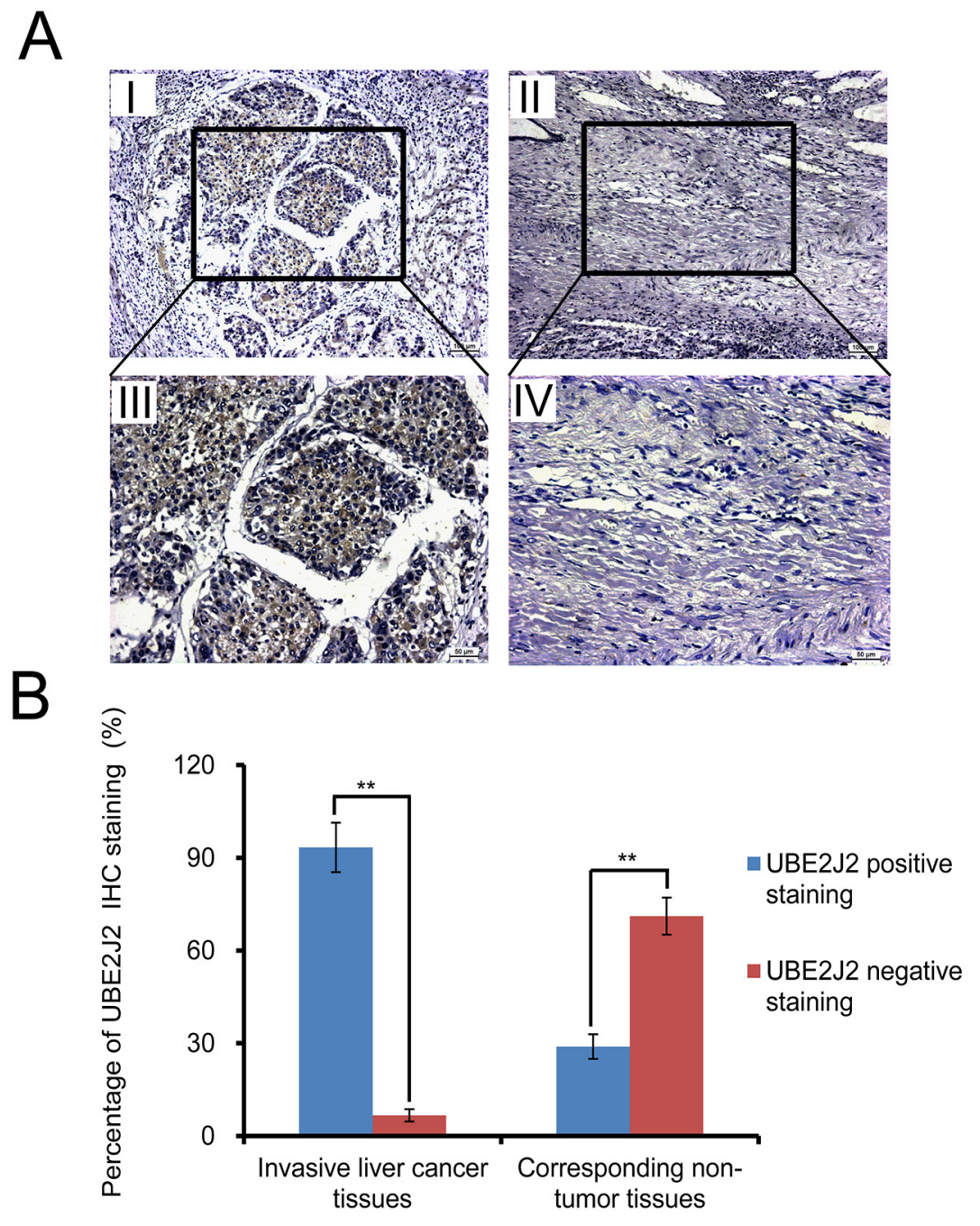

Figure 3: IHC analysis of UBE2J2 in invasive HC and corresponding non-tumor tissues. (A) Paraffin-embedded metastasized HC tissue sections were stained with DAB. HC tissues (I. \& III.) mostly stained positive for UBE2J2 (score >2). Positive staining was infrequent in corresponding non-tumor tissues (II. \& IV.). Scale bar $=100 \mu \mathrm{m}$ for (I, II), 50 $\mu \mathrm{m}$ for (III, IV). (B) Statistical analysis of UBE2J2 staining in $\mathrm{HC}$ patient tissues. $* * P<0.01$. 
(Figure 10C). These results together suggest that UBE2J2regulated HCCLM3 cell invasion depends on p-EGFR.

\section{DISCUSSION}

Cellular protrusions are highly dynamic structures involved in cell invasion [9]. To investigate how cellular protrusions promote invasion, mRNA from HCCLM3 cell protrusions and cell bodies was analyzed by direct RNA sequencing (DRS). Of the first four genes in these results not yet associated with cell invasion, three (ATP6VOD1, STXBP2, and UBE2J2) are important for endocytosis [21-24].

Endocytosis negatively regulates cell-extracellular environment interactions and controls cell signaling, for example through EGFR degradation by mono-

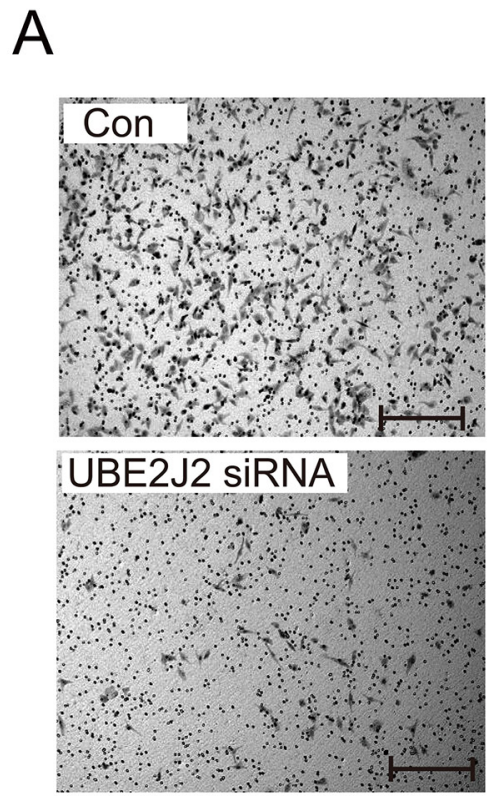

B

Figure 4: Effects of UBE2J2 knockdown on HCCLM3 cell invasion. HCCLM3 cells were transfected with UBE2J2 or scramble siRNA. Cells were seeded on Matrigel-coated chambers $24 \mathrm{~h}$ post-transfection. (A) Invaded cells were stained with $0.08 \%$ trypan blue. (B) Cells were counted in five random fields. Scale bar $=200 \mu \mathrm{m} . * * P<0.01$.

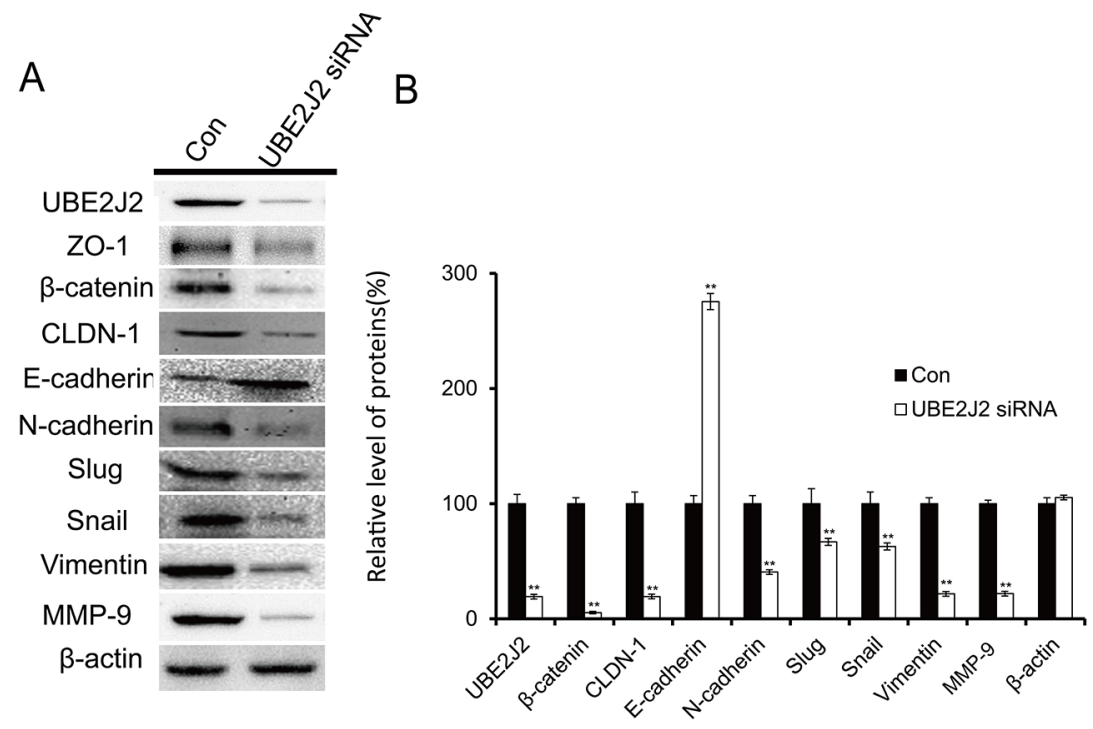

Figure 5: Effects of UBE2J2 knockdown on HCCLM3 cell MET. (A) Western blot analysis of UBE2J2, ZO-1, $\beta$-catenin, CLDN-1, E-cadherin, N-cadherin, slug, snail, vimentin, and MMP-9 levels. $\beta$-actin was used as loading control. (B) Densitometric analysis. Results are shown with respect to control. $* * P<0.01$. 
ubiquitination of receptor tyrosine kinases (RTKs) [28, 29], Ras activation [30, 31], caveolae-mediated TGF- $\beta$ receptor attenuation [32], and clathrin-dependent internalization [33]. Recent work has related endocytosis with cell invasion and motility. WNT5A promoted cancer cell invasion in a receptor-mediated endocytosisdependent manner [34]. Clathrin-mediated endocytosis is required for EGF-directed chemotactic invasion by MDAMB-231 cells [34] and Tannerella forsythia invasion in oral epithelial cells [35]. Integrin endocytosis is required for $\alpha v \beta 6$-mediated carcinoma cell migration and invasion [36]. Based on these findings and our DRS results, we hypothesized that ATP6VOD1, STXBP2, and UBE2J2 might regulate $\mathrm{HC}$ cell invasion and metastasis.

Western blotting and RT-qPCR analyses showed that UBE2J2 was highly expressed in HCCLM3 cell protrusions. STXBP2 and ATP6V0D1 were also highly expressed (data not shown here). IHC analyses showed
UBE2J2-positive staining in most $\mathrm{HC}$ tissues compared with corresponding non-tumor tissues (Figure 3), indicating that UBE2J2 might be a useful biomarker for $\mathrm{HC}$ diagnosis. UBE2J2 was silenced in HCCLM3 cells using specific siRNA, and cell invasion was measured via Boyden chamber assay. Invasion was decreased in silenced cells, indicating that UBE2J2 regulates HCCLM3 cell invasion.

The EMT-MET switch is fundamental to tumor metastasis [37]. EMT allows cancer cells in the primary tumor site to break through the basement membrane and enter the bloodstream through intravasation [38]. Invasive tumor cells that survive this process usually undergo MET within the new environment. Because UBE2J2 promotes HCCLM3 cell invasion, we assessed whether or not UBE2J2 knockdown might induce MET in these cells. We found that numerous MET biomarkers, including $\beta$-catenin, CLDN-1,
A

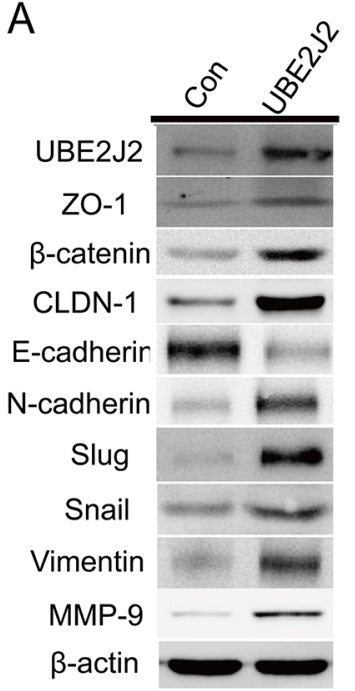

C

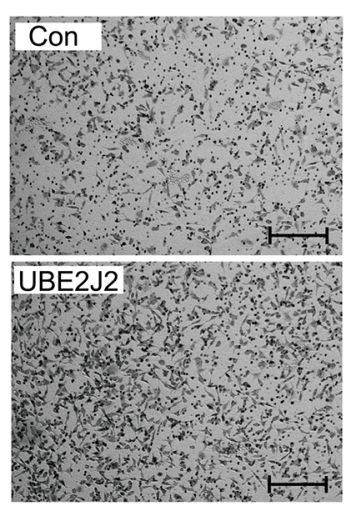

B

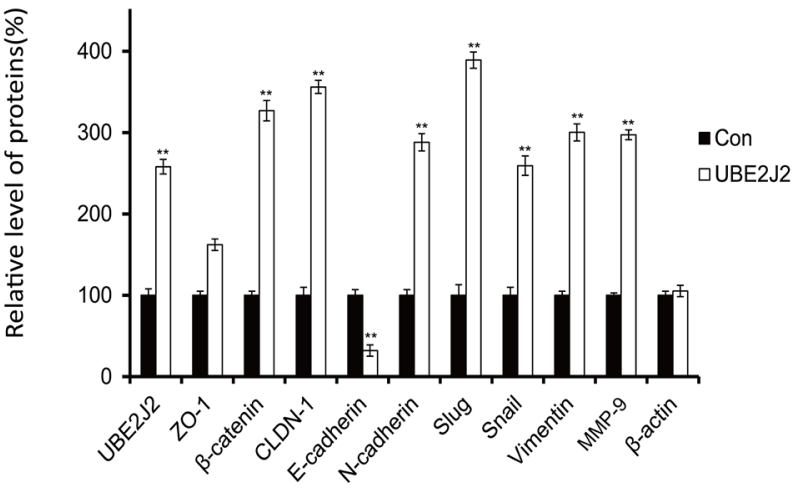

D

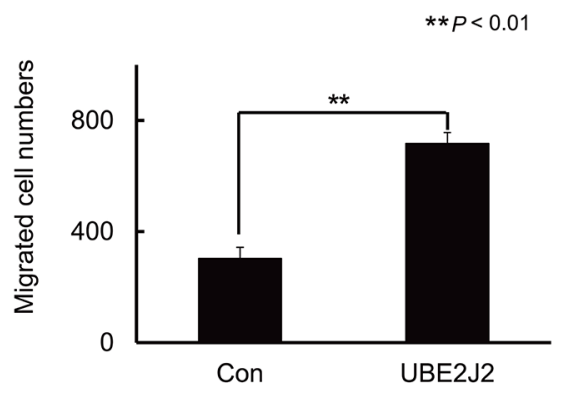

Figure 6: Effects of UBE2J2 overexpression on SMMC7721 cell EMT and invasion. (A) Western blot analysis of EMT biomarker levels. $\beta$-actin was used as loading control. (B) Densitometric analysis. Results are shown with respect to control. Cells that invaded through the membrane were stained with $0.08 \%$ trypan blue (C) and counted (D). Scale bar represents $200 \mu \mathrm{m}$. **P<0.01. 
A

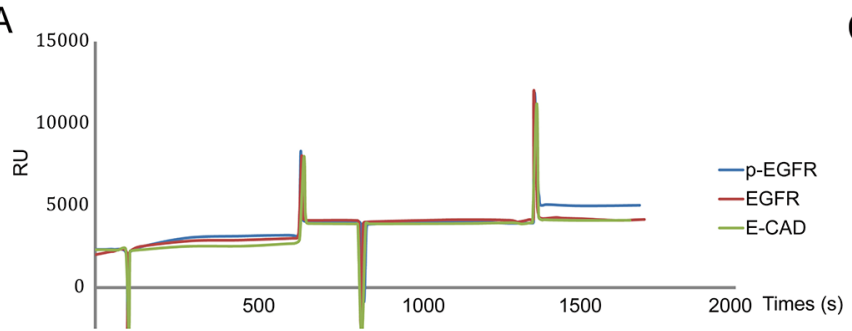

B

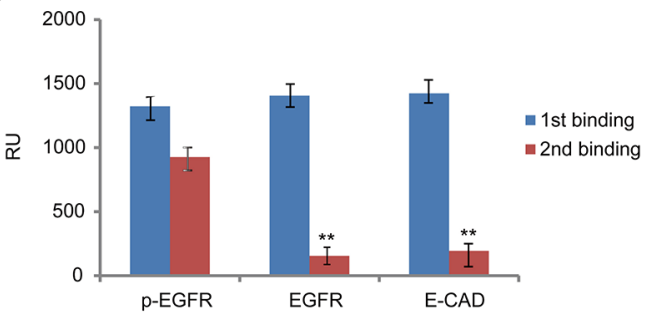

C

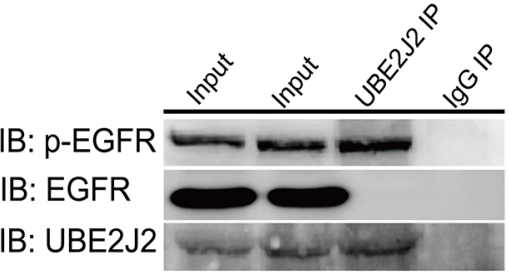

D

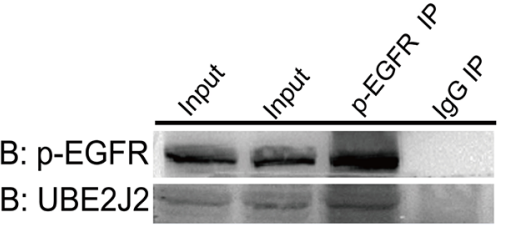

$E$

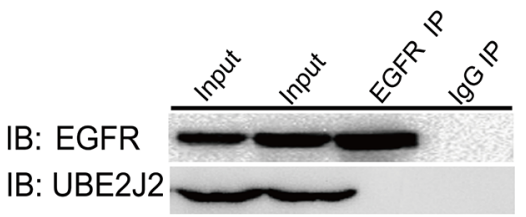

Figure 7: UBE2J2 and p-EGFR SPR and Co-IP analyses. (A) SPR analysis by Biacore X100.Anti-UBE2J2 antibody was immobilized onto a CM5 chip, followed by cell lysate protein binding and various antibodies. (B) SPR binding quantification. (C) The p-EGFR-UBE2J2 complex was pulled down by anti-UBE2J2, anti-p-EGFR, and anti-EGFR antibodies, and examined via immunoblotting. $\operatorname{IgG}$ was used as negative control.

A

HE
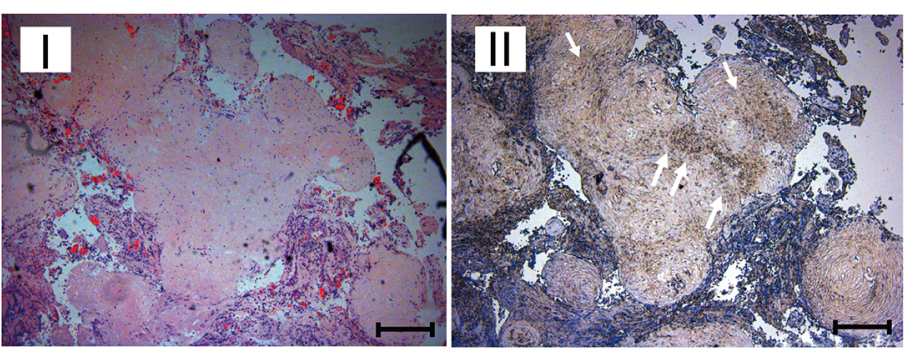

p-EGFR

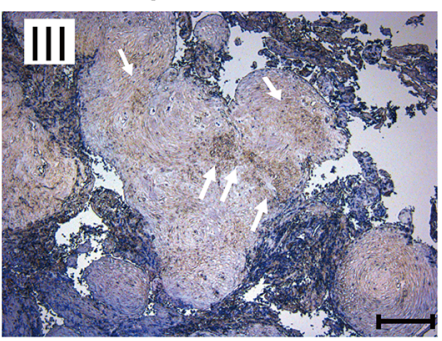

$\mathrm{B}$

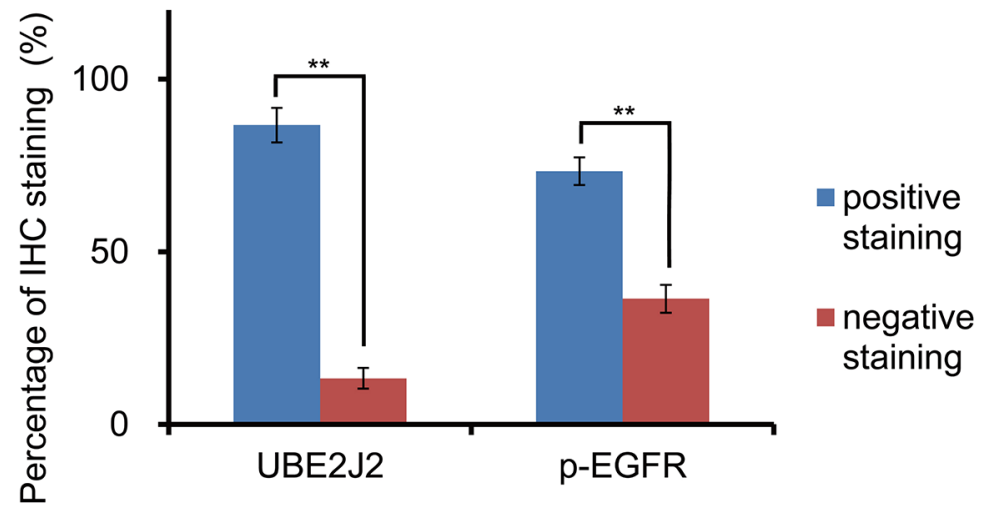

Figure 8: UBE2J2 and p-EGFR expression in invasive HC serial sections. (A) Paraffin-embedded metastasized HC tissue serial sections were stained with H\&E and DAB. H\&E staining cells (I). UBE2J2 staining cells (II). p-EGFR staining cells (III). Scale bar $=250 \mu \mathrm{m}$. (B) Statistical analysis of UBE2J2 and p-EGFR positive staining. ${ }^{*} P<0.01$. 
A

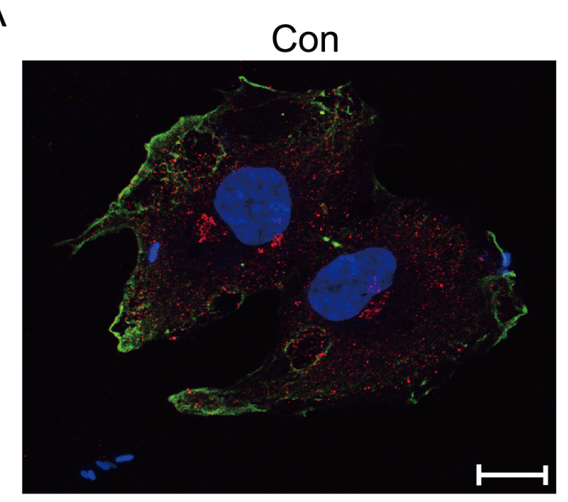

B

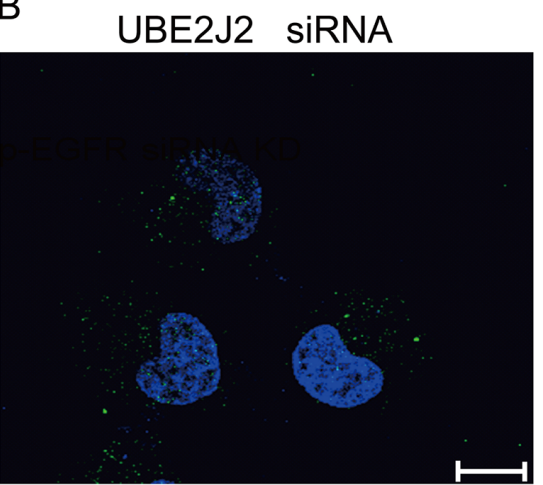

Green: p-EGFR Red: transferrin Blue: H33342
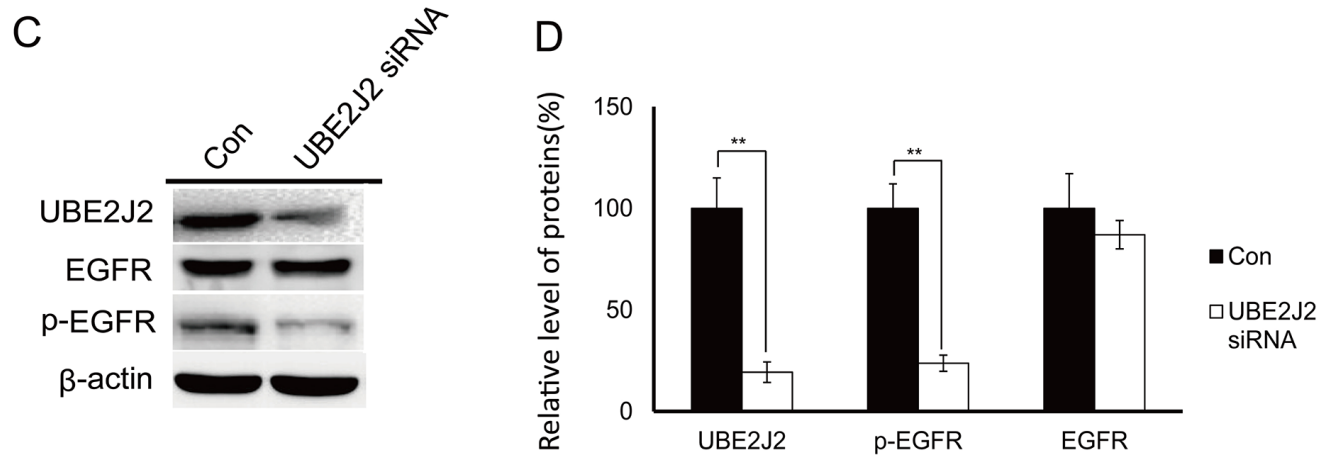

Figure 9: p-EGFR expression in UBE2J2-silenced HCCLM3 cells. HCCLM3 cells were transfected with scramble (A) or UBE2J2 siRNA (B) for $24 \mathrm{~h}$. Cells were starved for $3 \mathrm{~h}$, treated with transferrin $(5 \mathrm{mg} / \mathrm{ml}$, red) for $30 \mathrm{~min}$, and then stained with anti-pEGFR antibody (green) and H33342 (blue). Scale bars $=5 \mu \mathrm{m}$.(C) UBE2J2 and p-EGFR western blot analysis. (D) Densitometric analysis. Results are shown with respect to control. $* * P<0.01$.
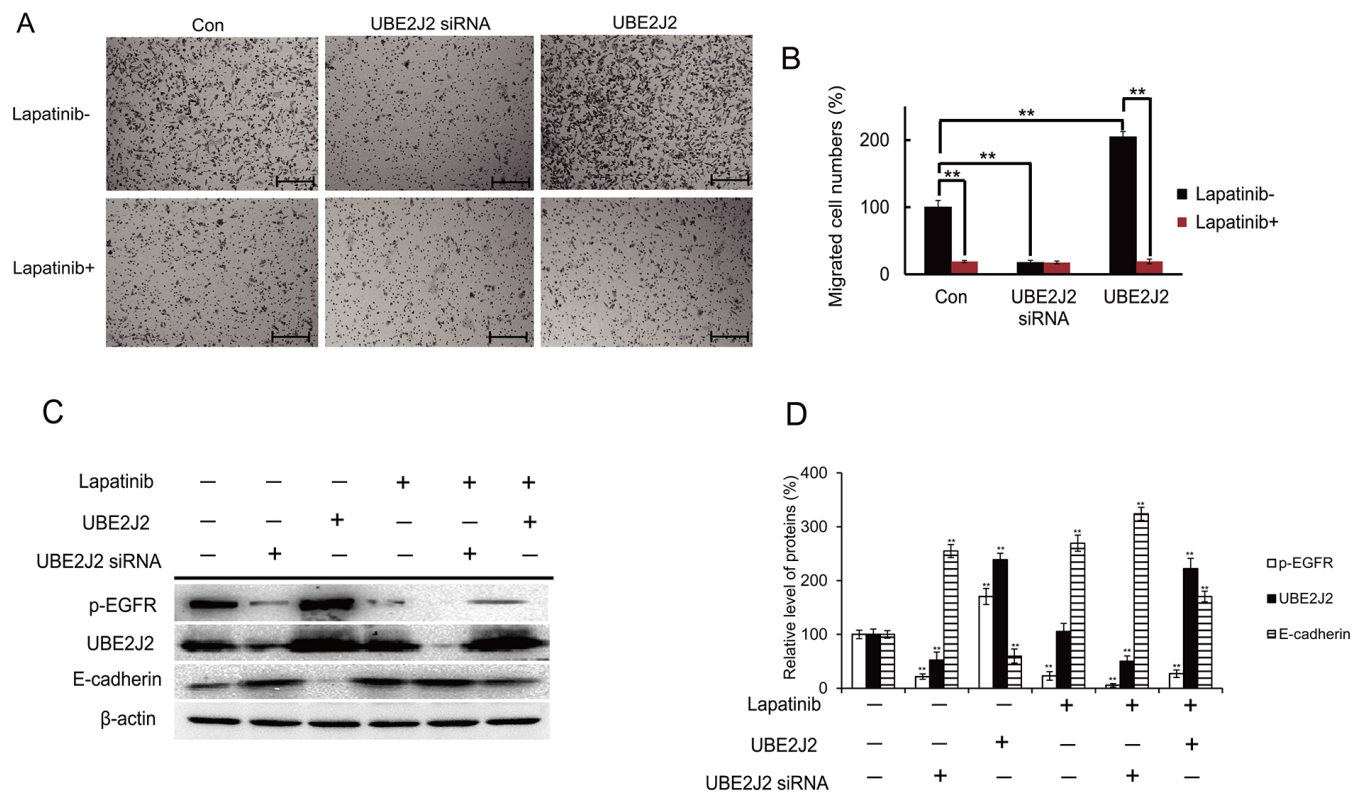

Figure 10: Effects of p-EGFR on UBE2J2-mediated HCCLM3 cell invasion. HCCLM3 cells were treated with vehicle or Lapatinib (10 nM) for $24 \mathrm{~h}$, followed by UBE2J2 knockdown or overexpression. (A) Cell invasion as assessed via Boyden chamber assay. (B) Migrated cells were counted. Scale bar $=200 \mu \mathrm{m}$. (C) Western blot analysis of the indicated proteins. (D) Densitometric analysis. Results are shown with respect to control. ${ }^{*} P<0.01$. 
N-cadherin, slug, snail, vimentin, ZO-1, MMP-9, were downregulated following UBE2J2 knockdown, and E-cadherin was upregulated. UBE2J2 overexpression in non-invasive SMMC7721 cells appeared to induce EMT and cell invasion, indicating that UBE2J2 regulates the EMT-MET switch.

To explore potential mechanisms of UBE2J2regulated HCCLM3 cell invasion, we screened for UBE2J2-interacting proteins using chip-based SPR. Numerous cell invasion-related protein antibodies were tested, but only p-EGFR bound UBE2J2. p-EGFR controls cell invasion via AKT and MMPs [39, 40]. We assessed HC cell invasion and protein levels following UBE2J2 silencing or p-EGFR inhibition. While p-EGFR levels appeared dependent on UBE2J2 expression, p-EGFR inhibition reduced UBE2J2promoted HCCLM3 cell invasion. Our findings indicate that UBE2J2 binds p-EGFR to promote HCCLM3 cell invasion.

Transferrin is an endocytosis indicator [41]. We found that UBE2J2 knockdown suppressed transferrin endocytosis. Because UBE2J2 also promotes $\mathrm{HC}$ cell invasion, we hypothesize that endocytosis is closely related to invasion. Protein ubiquitin (UB) modification is an important aspect of endocytosis [42]. Proteins secreted by other cells are captured by cell membrane receptors, internalized via endocytosis, sorted, and degraded by proteases in the lysosome $[12,42]$. Our study confirmed that UBE2J2 positively regulates $\mathrm{HC}$ cell endocytosis. p-EGFR reportedly stabilizes snail and slug to trigger EMT and tumor metastasis [43]. We showed that UBE2J2 binds p-EGFR to promote HC cell invasion and EMT. The UBE2J2 hydrophobic carboxyl terminus anchors to the ER membrane and associates with ubiquitin ligases to degrade cargo proteins in the lysosome [44]. Based on information from the microenvironment, cells make adjustments, such as triggering EMT or MET, reorganizing actin and tubulin, reconstructing cytoskeletons, and migrating (Figure 11).

In conclusion, the p-EGFR-UBE2J2 complex appears to promote HCCLM3 cell invasion and endocytosis. Our findings demonstrate that endocytosis in $\mathrm{HC}$ cells is closely related to invasion, and may provide new anti-HC therapeutic targets. UBE2J2 may also be a novel biomarker for clinical HC diagnosis.

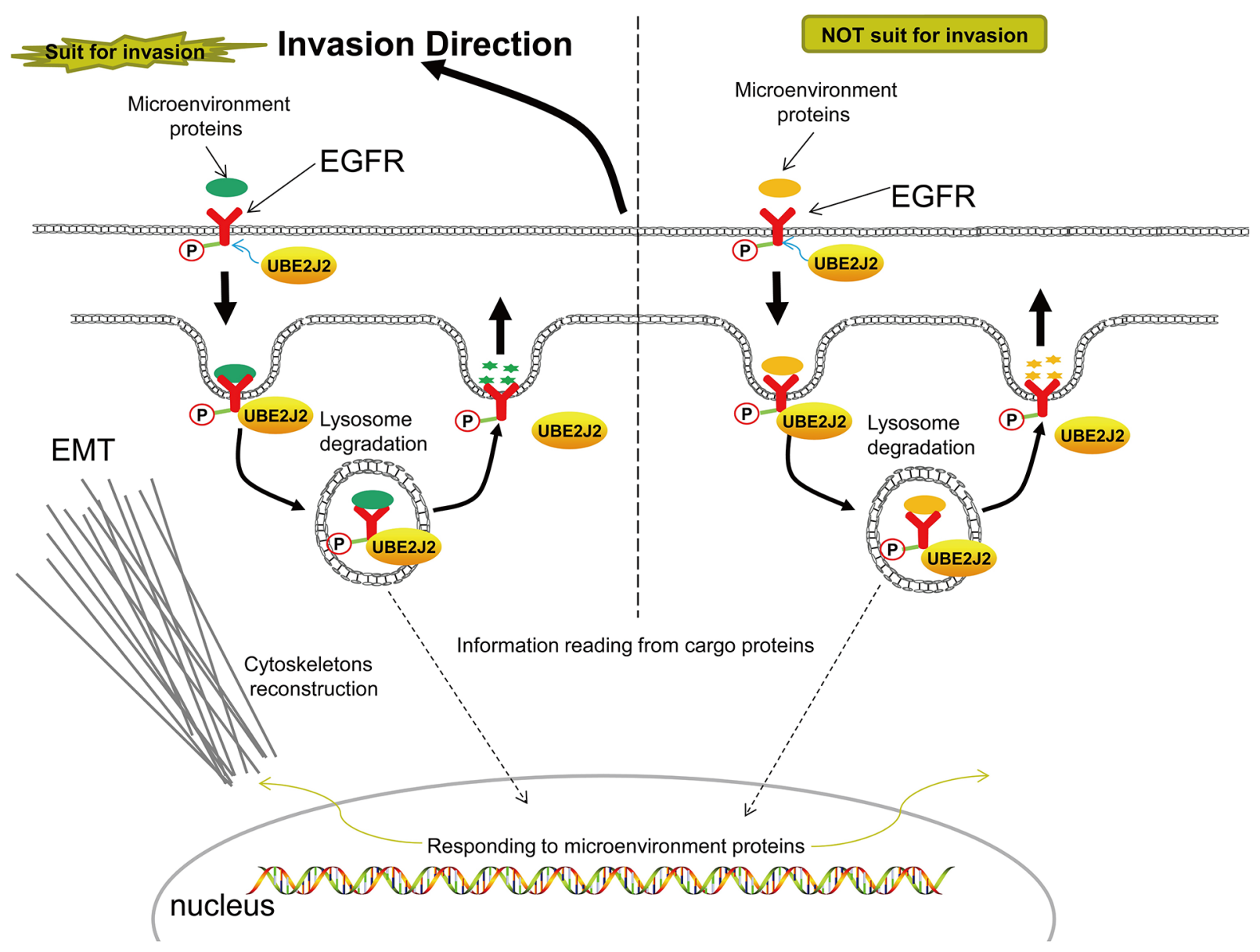

Figure 11: Proposed mechanism of UBE2J2-mediated HCCLM3 cell invasion and endocytosis. 


\section{MATERIALS AND METHODS}

\section{Cell culture}

Cell culture supplies were purchase from Life Technologies (Carlsbad, USA) and Corning (New York, USA). Human liver cancer cell lines, HCCLM3 and SMMC7721, were bought from the cell bank at the Chinese Academy of Sciences. Cells were grown in DMEM supplemented with $10 \% \mathrm{FBS}$, in an incubator with $5 \% \mathrm{CO}_{2}$ at $37^{\circ} \mathrm{C}$.

\section{Protrusion isolation and direct RNA sequencing (DRS)}

Cellular protrusion and cell body mRNA was extracted as described [19]. Cells were seeded on invasion inserts with $1 \mu \mathrm{m}$ pore membranes (from $\mathrm{BD}$ Company). Twelve $h$ after cells reached confluence, cellular protrusions were cut using a cell scraper, and mRNA was extracted using TRIzol. DRS was conducted via BGI RNA-Seq (Quantification) Analysis (BGI Tech, Shenzhen, China). The experiment was repeated three times and genes not detected at any time were excluded. More than 7,500 genes were analyzed and listed according to the ratio of expression in protrusions (HP) versus cell bodies (HB).

\section{Cell invasion assay}

Cell invasion assays were performed as described $[45,46]$. Invasion inserts with $8 \mu \mathrm{m}$ pore membranes (Corning, New York, USA) were coated with fibronectin (Sigma-Aldrich, Missouri, USA) as described [47]. Cells were pretreated with a specific or control siRNA for $6 \mathrm{~h}$. Pretreated cells were seeded onto inserts to reach confluence in $12 \mathrm{~h}$, and then cultured for another $24 \mathrm{~h}$. After fixation with $4 \%$ formaldehyde, non-invading cells on the upper sides of membranes were removed by cotton swab. Invading cells were stained with $0.08 \%$ trypan blue for $15 \mathrm{~min}$ as described [46] and photographed using a bright-field light microscope. Cells were counted in five random fields using Image-Pro Plus 6.0 from Media Cybernetics (MD, USA).

\section{RT-qPCR}

Cells were treated with specific or control siRNA for $24 \mathrm{~h}$ and total RNA was extracted using RNAzol as described [19]. cDNA was obtained using the PrimeScriptTM RT Reagent Kit (Takara, Dalian, China). UBE2J2 was amplified by RT-PCR using the KAPA SYBR Fast qPCR Kit (MA, USA) and measured using the 7500 Fast Real-Time PCR System (ABI, Massachusetts, USA). The following primers were used: UBE2J2 forward: 5'-TCTGTCTCCACCATCCTGACTG-3', reverse: 5'-GCTAAACTCTGCACTGCCAGTTG-3'; GAPDH forward: 5'-GTCTCCTCTGACTTCAACAGCG-3', reverse: 5'-ACCACCCTGTTGCTGTAGCCAA-3'. Primers were synthesized by Life Technologies (Massachusetts, USA). Gene expression was analyzed using the $2^{-\Delta \Delta C t}$ method as described [48].

\section{Western blotting}

Cells were lysed in RIPA buffer to extract whole-cell proteins [49]. Protein concentrations were measured using the DC Protein Assay Kit I (Bio-Rad, California, USA). Equal amounts of protein were subjected to $10 \%$ SDS polyacrylamide gel electrophoresis, and then transferred to PVDF membranes. The following primary antibodies were used: UBE2J2 (Millipore, Massachusetts, USA), EMT antibody kit, EGFR, and p-EGFR (Tyr1068) (Cell Signaling, Massachusetts, USA). Horseradish peroxidaseconjugated secondary antibody signals were detected and measured using the Luminescent Image Analyzer Tanon 5200 (Shanghai, China). Band densities were measured via ImageQuant software (Molecular Dynamics, Sunnyvale, CA, USA), and expressed as percentage of the $\beta$-actin band density.

\section{siRNA-mediated gene silencing}

siRNA oligos were designed and synthesized by GenePharma Company. Specific siRNAs included: UBE2J2: 5'-CCAGAGAAUUUCCUUUCAATT-3' and 5'-UUGAAAGGAAAUUCUCUGGTT-3'; negative control: 5'-UUCUCCGAACGUGUCACGUTT-3' and 5'-ACGUGACACGUUCGGAGAATT-3'; GAPDH positive control: 5'-UGACCUCAACUACAUGGUUTT-3' and 5'-AACCAUGUAGUUGAGGUCATT3'. SiRNA oligos were co-transfected into cells with Lipofectamine 2000 as described [19]. Cell lysates were analyzed using western blotting and RT-qPCR. Invasion rates of cells treated with specific or control siRNAs were measured via Boyden chamber assay. ANOVA was performed to evaluate differences between controls and siRNA knockdown groups, followed by Tukey post hoc analysis using Prism (GraphPad).

\section{$U B E 2 J 2$ cloning and overexpression}

UBE2J2 plasmid was constructed by cloning the $U B E 2 J 2$ PCR amplicon with specific primers into the $\mathrm{XbaI}$ site in the pEGFP-N3 plasmid (Clontech). UBE2J2 forward cloning primer: 5'-GCTCTAGAGCATGACCC CTTATGAAGGTGG-3', and reverse: 5'-GCTCTAGA GCTCACTCCTGCGCGATGCT-3'. After ligation, the amplicon was transfected into DH5 $\alpha$ competent cells followed by plasmid extraction and transient transfection of UBE2J2 into SMMC7721 cells using Lipofectamine 2000 as described [20]. After $24 \mathrm{~h}$ transfection, cells were subjected to Boyden chamber assay to assess cell invasion. Cell lysates were analyzed via western blotting 
with EMT biomarker antibodies to examine the effects of UBE2J2 on EMT.

\section{Immunohistochemistry (IHC)}

Forty-five paraffin-embedded hepatoma and corresponding non-tumor tissue sections were obtained from Shanghai Outdo Biotech Company (Shanghai, China) and Fuyong hospital (Shenzhen, China). Sections were deparaffinized using dimethylbenzene, 100\% ethanol, $90 \%$ ethanol, $80 \%$ ethanol, and $70 \%$ ethanol, followed by EDTA antigen retrieval and blocking. EDTA antigen retrieval solution was purchased from Beyotime (Suzhou, China) and the double standard blockers were from JianCheng Bioengineering Institute (Nanjing, China). Tissue sections were incubated with primary antibodies (1:200), washed, incubated with secondary antibodies $(1: 200)$, and then stained using 3,3'-Diaminobenzidine (DAB; JianCheng Bioengineering Institute, Nanjing, China) and hematoxylin (BaSo Company, Taiwan). Stained sections were analyzed and classified using a 5-point scoring system as described [25]. A score $>2$ points was considered positive staining. For serial section IHC staining, serial sections from 15 invasive HCs (provided by Fuyong Hospital, Shenzhen, China) were stained with hematoxylin and eosin (H\&E), and anti-UBE2J2, and anti-p-EGFR antibodies.

\section{Chip-based surface plasmon resonance (SPR)}

UBE2J2-associated proteins were screened using a Biacore X100 SPR sensor (Biacore, Uppsala, Sweden) as described [50]. Anti-UBE2J2 antibody and normal $\operatorname{IgG}$ were immobilized to a CM5 research-grade sensor chip (carboxymethyldextran-derivatized surface) using the standard EDC/NHS [N-ethyl-N"-(dimethylaminopropyl) carbodiimide/N-hydroxysuccinimide] coupling method [51]. The CM5 Chip was blocked with 3\% BSA to prevent nonspecific binding. Cells were lysed using RIPA buffer. Proteins were pre-concentrated using an ultrafiltration tube (Milipore), and then injected into the microfluidic system. After washing with HEPES buffer (50 mM HEPES, $\mathrm{pH}$ $7.4,150 \mathrm{mM} \mathrm{NaCl}$ ), UBE2J2 and any associated proteins remained on the CM5 Chip surface. $\beta$-catenin, CLDN-1, N-cadherin, E-Cadherin, slug, snail, vimentin, EGFR, p-EGFR, MMP-9, and MMP-2 antibodies were used to detect these cell invasion-related proteins. The process was automated using control software for the Biacore X100.

\section{Immunofluorescence staining}

HCCLM3 cells were cultured in glass bottom dishes and transfected with UBE2J2 siRNA for $24 \mathrm{~h}$ using Lipofectamine 2000 as described [19]. After $3 \mathrm{~h}$ of serumfree starvation, cells were treated with transferrin (20ug/ $\mathrm{ml}$ ) for $30 \mathrm{~min}$. Cells were fixed with $4 \%$ formaldehyde for $15 \mathrm{~min}$ and permeabilized with $0.25 \%$ Triton X-100 [52]. Cells were incubated with p-EGFR primary and
Dylight 488 Donkey Anti-Rabbit secondary antibodies as described [53, 54]. Cells were examined using an Olympus confocal laser-scanning microscope and images were analyzed using IPP6.0 (Image-Pro Plus 6.0).

\section{Statistical analysis}

Data are expressed as means \pm standard deviation (SD) of three independent experiments, and were analyzed with SPSS software using Student's t test. $P<0.05$ was considered statistically significant.

\section{ACKNOWLEDGMENTS}

We thank Violet Tafadzwa Senderai for copy editing assistance.

\section{CONFLICTS OF INTEREST}

The authors declare no conflicts of interest.

\section{GRANT SUPPORT}

This study was supported by grants from the National Natural Science Foundation of China (No.21272134), Science Technology and Innovation Committee of Shenzhen Municipality (No.CXZZ20150529165045064), Shenzhen Municipal government (JCYJ20160301153959476), China Scholarship Council, Shenzhen Municipal Development and Reform Commission (Disciplinary Development Program for Chemical Biology).

\section{REFERENCES}

1. Parkin DM, Bray F, Ferlay J, Pisani P. Global cancer statistics, 2002. CA Cancer J Clin. 2005; 55:74-108.

2. Peck-Radosavljevic M. Drug therapy for advanced-stage liver cancer. Liver Cancer. 2014; 3:125-31.

3. Mehlen P, Puisieux A. Metastasis: a question of life or death. Nat Rev Cancer. 2006; 6:449-58.

4. Klein CA. Cancer. The metastasis cascade. Science. 2008; 321:1785-87.

5. Byles V, Zhu L, Lovaas JD, Chmilewski LK, Wang J, Faller DV, Dai Y. SIRT1 induces EMT by cooperating with EMT transcription factors and enhances prostate cancer cell migration and metastasis. Oncogene. 2012; 31:4619-29.

6. Sánchez-Tilló E, Liu Y, de Barrios O, Siles L, Fanlo L, Cuatrecasas M, Darling DS, Dean DC, Castells A, Postigo A. EMT-activating transcription factors in cancer: beyond EMT and tumor invasiveness. Cell Mol Life Sci. 2012; 69:3429-56

7. Baldassarre M, Ayala I, Beznoussenko G, Giacchetti G, Machesky LM, Luini A, Buccione R. Actin dynamics at sites of extracellular matrix degradation. Eur J Cell Biol. 2006; 85:1217-31. 
8. Lizárraga F, Poincloux R, Romao M, Montagnac G, Le Dez G, Bonne I, Rigaill G, Raposo G, Chavrier P. Diaphanousrelated formins are required for invadopodia formation and invasion of breast tumor cells. Cancer Res. 2009; 69:2792-800.

9. Buccione R, Caldieri G, Ayala I. Invadopodia: specialized tumor cell structures for the focal degradation of the extracellular matrix. Cancer Metastasis Rev. 2009; 28:137-49.

10. Klemke RL. Trespassing cancer cells: 'fingerprinting' invasive protrusions reveals metastatic culprits. Curr Opin Cell Biol. 2012; 24:662-69.

11. Smith MH, Ploegh HL, Weissman JS. Road to ruin: targeting proteins for degradation in the endoplasmic reticulum. Science. 2011; 334:1086-90.

12. Tiwari S, Weissman AM. Endoplasmic reticulum (ER)associated degradation of $\mathrm{T}$ cell receptor subunits. Involvement of ER-associated ubiquitin-conjugating enzymes (E2s). J Biol Chem. 2001; 276:16193-200.

13. Lenk U, Yu H, Walter J, Gelman MS, Hartmann E, Kopito $\mathrm{RR}$, Sommer T. A role for mammalian Ubc6 homologues in ER-associated protein degradation. J Cell Sci. 2002; 115:3007-14.

14. Kim BW, Zavacki AM, Curcio-Morelli C, Dentice M, Harney JW, Larsen PR, Bianco AC. Endoplasmic reticulumassociated degradation of the human type 2 iodothyronine deiodinase (D2) is mediated via an association between mammalian UBC7 and the carboxyl region of D2. Mol Endocrinol. 2003; 17:2603-12.

15. Imai Y, Soda M, Inoue H, Hattori N, Mizuno Y, Takahashi R. An unfolded putative transmembrane polypeptide, which can lead to endoplasmic reticulum stress, is a substrate of Parkin. Cell. 2001; 105:891-902.

16. Imai Y, Soda M, Hatakeyama S, Akagi T, Hashikawa T, Nakayama KI, Takahashi R. CHIP is associated with Parkin, a gene responsible for familial Parkinson's disease, and enhances its ubiquitin ligase activity. Mol Cell. 2002; 10:55-67.

17. Wu CJ, Conze DB, Li X, Ying SX, Hanover JA, Ashwell JD. TNF-alpha induced c-IAP1/TRAF2 complex translocation to a Ubc6-containing compartment and TRAF2 ubiquitination. EMBO J. 2005; 24:1886-98.

18. Claessen JH, Mueller B, Spooner E, Pivorunas VL, Ploegh HL. The transmembrane segment of a tail-anchored protein determines its degradative fate through dislocation from the endoplasmic reticulum. J Biol Chem. 2010; 285:20732-39.

19. Liu YH, Jin JL, Wang YZ, Tan Y, Zhou YY, Peng T, Li F, Liang WD, Chartrand P, Jiang YY, Shen ZF. Protrusionlocalized STAT3 mRNA promotes metastasis of highly metastatic hepatocellular carcinoma cells in vitro. Acta Pharmacol Sin. 2016; 37:805-13.

20. Taxman DJ, Holley-Guthrie EA, Huang MT, Moore CB, Bergstralh DT, Allen IC, Lei Y, Gris D, Ting JP. The NLR adaptor ASC/PYCARD regulates DUSP10, mitogenactivated protein kinase (MAPK), and chemokine induction independent of the inflammasome. J Biol Chem. 2011; 286:19605-16.

21. Spessott WA, Sanmillan ML, McCormick ME, Patel N, Villanueva J, Zhang K, Nichols KE, Giraudo CG. Hemophagocytic lymphohistiocytosis caused by dominantnegative mutations in STXBP2 that inhibit SNAREmediated membrane fusion. Blood. 2015; 125:1566-77.

22. Breton $\mathrm{S}$, Brown D. Regulation of luminal acidification by the V-ATPase. Physiology (Bethesda). 2013; 28:318-29.

23. Kane PM. The where, when, and how of organelle acidification by the yeast vacuolar $\mathrm{H}+$-ATPase. Microbiol Mol Biol Rev. 2006; 70:177-91.

24. Wang X, Herr RA, Rabelink M, Hoeben RC, Wiertz EJ, Hansen TH. Ube2j2 ubiquitinates hydroxylated amino acids on ER-associated degradation substrates. J Cell Biol. 2009; 187:655-68.

25. Wachtel $M$, Runge $T$, Leuschner I, Stegmaier $S$, Koscielniak E, Treuner J, Odermatt B, Behnke S, Niggli FK, Schäfer BW. Subtype and prognostic classification of rhabdomyosarcoma by immunohistochemistry. J Clin Oncol. 2006; 24:816-22.

26. Borch J, Roepstorff P. Combinations of SPR and MS for characterization of native and recombinant proteins in cell lysates. Mol Biotechnol. 2006; 33:179-90.

27. Mimura K, Kono K, Maruyama T, Watanabe M, Izawa S, Shiba S, Mizukami Y, Kawaguchi Y, Inoue M, Kono T, Choudhury A, Kiessling R, Fujii H. Lapatinib inhibits receptor phosphorylation and cell growth and enhances antibody-dependent cellular cytotoxicity of EGFR- and HER2-overexpressing esophageal cancer cell lines. Int J Cancer. 2011; 129:2408-16.

28. Haglund K, Sigismund S, Polo S, Szymkiewicz I, Di Fiore PP, Dikic I. Multiple monoubiquitination of RTKs is sufficient for their endocytosis and degradation. Nat Cell Biol. 2003; 5:461-66.

29. Dikic I, Szymkiewicz I, Soubeyran P. Cbl signaling networks in the regulation of cell function. Cell Mol Life Sci. 2003; 60:1805-27.

30. Yusoff P, Lao DH, Ong SH, Wong ES, Lim J, Lo TL, Leong HF, Fong CW, Guy GR. Sprouty2 inhibits the Ras/MAP kinase pathway by inhibiting the activation of Raf. J Biol Chem. 2002; 277:3195-201.

31. Sasaki A, Taketomi T, Kato R, Saeki K, Nonami A, Sasaki M, Kuriyama M, Saito N, Shibuya M, Yoshimura A. Mammalian Sprouty4 suppresses Ras-independent ERK activation by binding to Raf1. Cell Cycle. 2003; 2:281-82.

32. Di Guglielmo GM, Le Roy C, Goodfellow AF, Wrana JL. Distinct endocytic pathways regulate TGF-beta receptor signalling and turnover. Nat Cell Biol. 2003; 5:410-21.

33. Mutch LJ, Howden JD, Jenner EP, Poulter NS, Rappoport JZ. Polarised clathrin-mediated endocytosis of EGFR during chemotactic invasion. Traffic. 2014; 15:648-64. 
34. Shojima K, Sato A, Hanaki H, Tsujimoto I, Nakamura M, Hattori K, Sato Y, Dohi K, Hirata M, Yamamoto H, Kikuchi A. Wnt5a promotes cancer cell invasion and proliferation by receptor-mediated endocytosis-dependent and -independent mechanisms, respectively. Sci Rep. 2015; 5:8042.

35. Mishima E, Sharma A. Tannerella forsythia invasion in oral epithelial cells requires phosphoinositide 3-kinase activation and clathrin-mediated endocytosis. Microbiology. 2011; 157:2382-91.

36. Ramsay AG, Keppler MD, Jazayeri M, Thomas GJ, Parsons M, Violette S, Weinreb P, Hart IR, Marshall JF. HS1associated protein $\mathrm{X}-1$ regulates carcinoma cell migration and invasion via clathrin-mediated endocytosis of integrin alphavbeta6. Cancer Res. 2007; 67:5275-84.

37. Huang L, Wu RL, Xu AM. Epithelial-mesenchymal transition in gastric cancer. Am J Transl Res. 2015; 7:2141-58.

38. Chaffer CL, Weinberg RA. A perspective on cancer cell metastasis. Science. 2011; 331:1559-64.

39. Qian L, Liu Y, Xu Y, Ji W, Wu Q, Liu Y, Gao Q, Su C. Matrine derivative WM130 inhibits hepatocellular carcinoma by suppressing EGFR/ERK/MMP-2 and PTEN/ AKT signaling pathways. Cancer Lett. 2015; 368:126-34.

40. Liu Y, Bi T, Shen G, Li Z, Wu G, Wang Z, Qian L, Gao Q. Lupeol induces apoptosis and inhibits invasion in gallbladder carcinoma GBC-SD cells by suppression of EGFR/MMP-9 signaling pathway. Cytotechnology. 2016; 68:123-33.

41. Schwake L, Henkel AW, Riedel HD, Schlenker T, Both M, Migala A, Hadaschik B, Henfling N, Stremmel W. Regulation of transferrin-induced endocytosis by wild-type and C282Y-mutant HFE in transfected HeLa cells. Am J Physiol Cell Physiol. 2002; 282:C973-79.

42. Funakoshi Y, Chou MM, Kanaho Y, Donaldson JG. TRE17/USP6 regulates ubiquitylation and trafficking of cargo proteins that enter cells by clathrin-independent endocytosis. J Cell Sci. 2014; 127:4750-61.

43. Balakrishnan S, Bhat FA, Raja Singh P, Mukherjee S, Elumalai P, Das S, Patra CR, Arunakaran J. Gold nanoparticle-conjugated quercetin inhibits epithelialmesenchymal transition, angiogenesis and invasiveness via EGFR/VEGFR-2-mediated pathway in breast cancer. Cell Prolif. 2016; 49:678-97.
44. Lam SY, Murphy C, Foley LA, Ross SA, Wang TC, Fleming JV. The human ubiquitin conjugating enzyme UBE2J2 (Ubc6) is a substrate for proteasomal degradation. Biochem Biophys Res Commun. 2014; 451:361-66.

45. Shan D, Chen L, Wang D, Tan YC, Gu JL, Huang XY. The $\mathrm{G}$ protein $\mathrm{G}$ alpha(13) is required for growth factor-induced cell migration. Dev Cell. 2006; 10:707-18.

46. Yang S, Huang XY. Ca2+ influx through L-type Ca2+ channels controls the trailing tail contraction in growth factor-induced fibroblast cell migration. J Biol Chem. 2005; 280:27130-37.

47. Kleinman HK. Preparation of basement membrane components from EHS tumors. Curr Protoc Cell Biol. 2001; Chapter 10:Unit 10.2. https://doi.org/10.1002/0471143030.cb1002s00.

48. Livak KJ, Schmittgen TD. Analysis of relative gene expression data using real-time quantitative PCR and the 2(-Delta Delta C(T)) Method. Methods. 2001; 25:402-08.

49. Pfrepper KI, Flügel RM. Molecular characterization of proteolytic processing of the Gag proteins of human spumaretrovirus. Methods Mol Biol. 2005; 304:435-44.

50. Hayano T, Yamauchi Y, Asano K, Tsujimura T, Hashimoto $\mathrm{S}$, Isobe T, Takahashi N. Automated SPR-LC-MS/MS system for protein interaction analysis. J Proteome Res. 2008; 7:4183-90.

51. Johnsson B, Löfås S, Lindquist G. Immobilization of proteins to a carboxymethyldextran-modified gold surface for biospecific interaction analysis in surface plasmon resonance sensors. Anal Biochem. 1991; 198:268-77.

52. Wu S, Divall S, Hoffman GE, Le WW, Wagner KU, Wolfe A. Jak2 is necessary for neuroendocrine control of female reproduction. J Neurosci. 2011; 31:184-92.

53. Speidl WS, Kastl SP, Hutter R, Katsaros KM, Kaun C, Bauriedel G, Maurer G, Huber K, Badimon JJ, Wojta J. The complement component $\mathrm{C} 5 \mathrm{a}$ is present in human coronary lesions in vivo and induces the expression of MMP-1 and MMP-9 in human macrophages in vitro. FASEB J. 2011; $25: 35-44$.

54. Zhang X, Wong SM. Hibiscus chlorotic ringspot virus upregulates plant sulfite oxidase transcripts and increases sulfate levels in kenaf (Hibiscus cannabinus L.). J Gen Virol. 2009; 90:3042-50. 